\title{
Erratum to: The comparison of laparoscopic pyelolithotomy and percutaneous nephrolithotomy in the treatment of solitary large renal pelvic stones
}

\author{
Ahmet Tefekli - Abdulkadir Tepeler - Tolga Akman • \\ Muzaffer Akçay • Murat Baykal • Mert Ali Karadağ • \\ Ahmet Y. Muslumanoglu • Jean de la Rosette
}

Published online: 7 July 2012

(C) Springer-Verlag 2012

\section{Erratum to: Urol Res}

DOI 10.1007/s00240-012-0463-5

Dr. Tefekli was affiliated to:

Department of Urology, Haseki Teaching and Research Hospital, 34360 Istanbul, Turkey
His current contact information is:

Department of Urology,

V.K.F. American Hospital, 34365 Istanbul, Turkey

e-mail: atefekli@yahoo.com

The online version of the original article can be found under doi:10.1007/s00240-012-463-5.

A. Tefekli · M. Baykal · A. Y. Muslumanoglu Department of Urology, Haseki Teaching and Research Hospital, 34360 Istanbul, Turkey

Present Address:

A. Tefekli $(\square)$

Department of Urology, V.K.F. American Hospital,

34365 Istanbul, Turkey

e-mail: atefekli@yahoo.com

\section{A. Tepeler · T. Akman · M. Akçay}

Department of Urology, Bezmialem Vakif University,

Istanbul, Turkey

M. A. Karadağ

Department of Urology, Kayseri State Hospital,

Kayseri, Turkey

J. de la Rosette

Department of Urology, AMC University Hospital,

Amsterdam, Netherlands 